\title{
Effect of prone position without PEEP on oxygenation and complacency in an experimental model of lung injury
}

\author{
Ana Cristina Z. Yagui, ${ }^{1}$ Oswaldo S. Beppu²
}

\begin{abstract}
Objective: To observe the effects of the prone position and the need for positive end-expiratory pressure (PEEP) to improve oxygenation.

Methods: Sixteen rats were anesthetized and ventilated at a tidal volume of $8 \mathrm{~mL} / \mathrm{kg}$, respiratory rate of $60 \mathrm{rpm}$ and PEEP $=0 \mathrm{cmH}_{2} \mathrm{O}$ (ZEEP), in the supine position for 30 minutes. Lung injury was then induced by means of intratracheal instillation of hydrochloric acid. Once the injury was established, rats were placed in the prone position for a further 30 minutes and randomized into two groups: in group 1 PEEP $=5 \mathrm{cmH}_{2} \mathrm{O}$ was added; while group 2 was kept on ZEEP. Measurements of pulmonary mechanics, arterial blood gas analysis and mean arterial pressure were taken at the end of each phase.

Results: In group 1, oxygen partial pressure increased significantly from $98.7 \pm 26.5$ to $173.9 \pm 58.4 \mathrm{mmHg}$ between injury and prone phases; in group 2 it was unchanged, varying from $99.6 \pm 15.4$ to $100.5 \pm 24.5 \mathrm{mmHg}$. Group 1 also exhibited significant improvement in complacency, from $0.20 \pm 0.01$ to $0.23 \pm 0.02 \mathrm{~mL} / \mathrm{cmH}_{2} \mathrm{O}$, while, once more, group 2 did not exhibit improvement, going from $0.21 \pm 0.02$ to $0.22 \pm 0.01 \mathrm{~mL} / \mathrm{cmH}_{2} \mathrm{O}$. Mean arterial blood pressure measurements did not change significantly in either group at any point during the experiment.

Conclusions: The prone position only resulted in improved oxygenation and respiratory mechanics when combined with PEEP $=5 \mathrm{cmH}_{2} \mathrm{O}$. The prone position did not cause hemodynamic compromise with or without PEEP = $5 \mathrm{cmH}_{2} \mathrm{O}$.
\end{abstract}

J Pediatr (Rio J). 2007; 83(4):343-348: Prone position, ARDS, PEEP.

\section{Introduction}

Secondary arterial hypoxemia, primarily caused by increased pulmonary shunt, is the principal physiological change that takes place during acute lung injury and acute respiratory distress syndrome (ARDS) and is an important element of its definition. ${ }^{1,2}$ A variety of ventilatory maneuvers are employed to combat it, such as mechanical ventilation with positive end expiratory pressure (PEEP), alveolar recruitment, high-frequency ventilation ${ }^{3-5}$ and non-ventilatory maneuvers such as the administration of nitric oxide and surfactant, fluids management, corticoids, ${ }^{5-8}$ etc.

The most effective measure for improving oxygenation is to employ PEEP, although the best method of administration is not yet known. ${ }^{9-11}$ It can, however, also be responsible for severe hemodynamic changes, to the extent that it can become a problem. Despite all of these measures, hypoxemia

1. Fisioterapeuta. Especialista em Fisioterapia Respiratória, Universidade Federal de São Paulo - Escola Paulista de Medicina (UNIFESP-EPM), São Paulo, SP, Brasil. Mestre, UNIFESP-EPM, São Paulo, SP, Brasil.

2. Professor adjunto, Disciplina de Pneumologia, UNIFESP-EPM, São Paulo, SP, Brasil.

Suggested citation: Yagui AC, Beppu OS. Effect of prone position without PEEP on oxygenation and complacency in an experimental model of lung injury. $J$ Pediatr (Rio J). 2007;83(4):343-348.

Manuscript received Nov 13 2006, accepted for publication Feb 282007.

doi 10.2223/JPED. 1648 
very often persists, and it becomes necessary to administer high fractions of inspired oxygen, within the range of toxicity, which in turn makes further measures necessary. Among these, the prone position is most efficient, and while its use has not been shown to reduce mortality, ${ }^{12-14}$ it has proven important for improving arterial oxygenation. ${ }^{15}$ In clinical trials it has been shown to improve oxygenation in $75-80 \%$ of patients and, because of this, has been recommended by consensus papers on mechanical ventilation for ARDS. ${ }^{5}$

In 1976, Piehl \& Brown performed a retrospective study demonstrating that the prone position improved oxygenation in five patients with ARDS without observing any deleterious effects. ${ }^{16}$ Around 1 year later, Douglas et al. performed a retrospective study demonstrating that the prone position could effectively improve oxygenation in ARDS. ${ }^{17}$ Many clinical and experimental studies have since been carried out, but the mechanism responsible for the improvement remains highly controversial. ${ }^{18,19}$ The relationship between PEEP, prone position and improved oxygenation is also controversial. $^{20}$

The objective of this study is to test whether the prone position in isolation, without PEEP, can improve arterial oxygenation in an experimental model of ARDS and, depending on the results, postulate the physiological mechanism behind any improvement.

\section{Methods}

The study protocol was submitted to and approved by the Ethics Committee at the Universidade Federal de São Paulo/ Escola Paulista de Medicina (UNIFESP-EPM), hearing $0172 / 04$. Sixteen male Wistar rats, with weights varying from 0.35 to $0.42 \mathrm{~kg}$, were obtained for the study from the central animal facility at UNIFESP-EPM. On the day of the experiment the rats were allocated to groups by lots. The rats were weighed (Agran balance, model 1715) and anesthetized with intraperitoneal sodium thiopental at a dosage of $50 \mathrm{mg} / \mathrm{kg}$, with supplementary doses given as necessary throughout the experiment. The carotid artery was catheterized with a polyethylene catheter maintained heparinized in order to measure mean arterial pressure (MAP), which was verified throughout the study using an invasive pressure monitor (AVS Model - special projects) and also for the collection of arterial blood for gas analysis. Samples of $200 \mu \mathrm{L}$ of arterial blood were taken for arterial blood gas analysis by Radiometer Copenhagen ABL 520 equipment at the following time points: baseline (first phase), injury (second phase) and prone (third phase). The pulmonary vein was also catheterized with the same type of polyethylene catheter and used for hydration with saline solution at a dosage of 10.0 $\mathrm{mL} / \mathrm{kg} / \mathrm{h}$, using a NIKKISO infusion pump. The rats were paralyzed with $0.1 \mathrm{~mL} / \mathrm{kg}$ of pancuronium bromide (Pavulon) and put on mechanical ventilation using an Inter 3 ventilator
(Intermed, Brazil) adapted for small animals, with fraction of inspired oxygen at $100 \%$, tidal volume (Vt) at around 8 $\mathrm{mL} / \mathrm{kg}$, respiratory rate at around $60 \mathrm{rpm}$, inspiratory flow at $10 \mathrm{~mL} / \mathrm{s}$ and PEEP $=0 \mathrm{cmH}_{2} \mathrm{O}$ (ZEEP), in the supine position for 30 minutes, which was defined as the baseline phase. In order to be included in the remainder of this study, each rat had to exhibit an initial $\mathrm{PaO}_{2} \geq 300 \mathrm{mmHg}$. Lung injury was induced by infusion of $1 \mathrm{~mL} / \mathrm{kg}$ of hydrochloric acid $(\mathrm{HCl})$ $(0.1 \mathrm{~N}$ with $\mathrm{pH}$ of 1.5$)$ in intratracheal bolus, with the rat disconnected from the mechanical ventilator in an inverted Trendelenburg position. The injury period began after infusion, but, if ARDS was not confirmed after 30 minutes $\left(\mathrm{PaO}_{2} \leq 200 \mathrm{mmHg}\right)$, then another $50 \%$ of the initial dose was infused and the rat kept on mechanical ventilation for a further 30 minutes until injury was confirmed. Three measurements were taken for each of peak pressure (Ppeak), PEEP and flow, and the means recorded, while Vt was calculated from figures obtained using a pneumotachograph (Hans Rudolph Inc., 0-3 LPM) connected between the ventilator and tracheostomy and also with data acquisition software (PicoScope). Dynamic complacency (Cdyn) measurements were then calculated using the following formula: Volume/Ppeak - PEEP. Once the injuries were established, rats were randomized into two groups: group 1 rats were put in the prone position and given PEEP = $5 \mathrm{cmH}_{2} \mathrm{O}$; while group 2 rats were put in the prone position and kept on PEEP $=0$ (ZEEP). This was designated as the third phase of the protocol and the rats remained in this state for a further 30 minutes. Results are expressed as means with standard deviations (SD). Student's t test for unpaired samples was used for comparisons between groups. Comparisons between phases within groups were made using analysis of variance for dependent data. When the test returned statistically significant values, it was supplemented with the Tukey-Kramer test. Instat software was used. The sample size was calculated assuming a variation of the order of $31 \mathrm{mmHg}$ (pilot phase) and seeking to detect a difference between the two groups of the order of $50 \mathrm{mmHg}$, resulting in eight animals in each group to achieve alpha $=0.005$ and beta $=0.80$.

\section{Results}

None of the animals died before the end of the experiment. Four of the rats were excluded from the experiment because their baseline $\mathrm{PaO}_{2}$ was $<300 \mathrm{mmHg}$. The two groups did not differ significantly in terms of the variables studied during the baseline period, either in terms of weight, gas exchange, pulmonary mechanics or MAP. In relation to gas exchange, both groups exhibited a significant drop in $\mathrm{PaO}_{2}$ between baseline and injury phases; group 1 exhibited significant improvement in $\mathrm{PaO}_{2}$ between injury and prone phases, as shown in Table 1 and Figure 1, which did not occur in group 2 . In regard to the respiratory mechanics 
variable, both groups exhibited a reduction in dynamic pulmonary compliance between baseline and injury phases (Table 1). Group 1 exhibited significant improvement in complacency between the injury and prone phases; however group 2 did not improve (Table 1, Figure 2). The hemodynamic variable (MAP measurement) did not exhibit significant changes in either group at any point during the experiment (Table 1).

\section{Discussion}

The response to PEEP and the prone position can vary between pulmonary and extrapulmonary ARDS, ${ }^{21,22}$ to the extent that interpretations of this study should take this fact into consideration. The model we have studied is more representative of pulmonary ARDS. Furthermore, the response may vary depending on whether infiltrates are localized or diffuse. ${ }^{23}$

Despite the need to use PEEP in ARDS to improve oxygenation and also to protect the lung injury induced or related to mechanical ventilation, we did not use it in the supine position for two reasons:

- The effects of PEEP in the supine position are well-known;

- Using PEEP in the supine position would recruit pulmonary alveoli and could result in hemodynamic changes, factors which could alter the interpretation of the results studied in the prone position.
$\mathrm{PaO}_{2}$ analysis $(\mathrm{mmHg})$

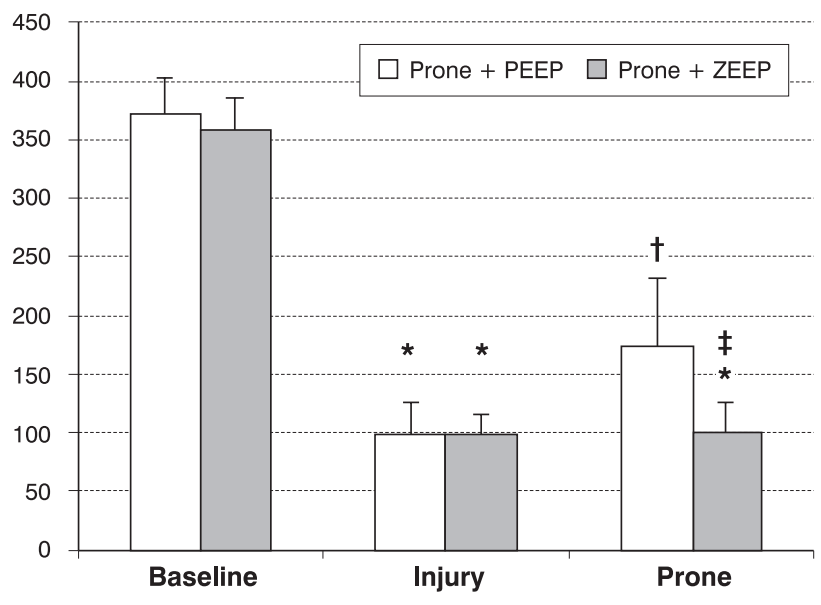

$* p \leq 0.001$ vs. baseline, ${ }^{\dagger} p \leq 0.05$ vs. injury, ${ }^{\ddagger} p \leq 0.05$ vs. G1.

Figure 1 - Oxygenation of the two groups

Furthermore, one of the objectives of this study was to postulate the mechanisms of response to oxygenation and mechanics in the prone position, which prior use of PEEP could have compromised. We used PEEP at a level of $5.0 \mathrm{cmH}_{2} \mathrm{O}$ based on our and on previous experiments. We observed that this level of PEEP already significantly improved arterial oxygenation ${ }^{23}$ and that, in this model, higher levels of PEEP

Table 1 - Analysis of study variables for groups $1\left(P E E P=5 \mathrm{cmH}_{2} \mathrm{O}\right)$ and 2 (ZEEP)

\begin{tabular}{|c|c|c|c|c|}
\hline Variables & Groups & Baseline (B) & Injury (I) & Prone (P) \\
\hline \multicolumn{5}{|c|}{$\mathrm{PaO}_{2}(\mathrm{mmHg})$} \\
\hline & G1 Prone + PEEP & $370.3 \pm 30.6$ & $98.7 \pm 26.5^{*}$ & $173.9 \pm 58.4^{*+}$ \\
\hline & G2 Prone + ZEEP & $356.4 \pm 28.6$ & $99.6 \pm 15.4 *$ & $100.5 \pm 24.5^{*^{\ddagger}}$ \\
\hline \multicolumn{5}{|c|}{ Cdyn $\left(\mathrm{mL} / \mathrm{cmH}_{2} \mathrm{O}\right)$} \\
\hline & G1 Prone + PEEP & $0.34 \pm 0.02$ & $0.20 \pm 0.01 *$ & $0.23 \pm 0.02^{*}$ \\
\hline & G2 Prone + ZEEP & $0.35 \pm 0.03$ & $0.21 \pm 0.02 *$ & $0.22 \pm 0.01 *$ \\
\hline \multicolumn{5}{|c|}{$\mathrm{MAP}(\mathrm{mmHg})$} \\
\hline & G1 Prone + PEEP & $142.6 \pm 25.0$ & $130.7 \pm 14.1$ & $125.8 \pm 22.0$ \\
\hline & G2 Prone + ZEEP & $143.1 \pm 23.6$ & $143.0 \pm 16.8$ & $130.8 \pm 34.8$ \\
\hline
\end{tabular}

Cdyn = dynamic complacency; $M A P=$ average arterial pressure; PEEP = positive end-expiratory pressure;

ZEEP $=$ PEEP $=0 \mathrm{cmH}_{2} \mathrm{O}$.

${ }^{*} p \leq 0.001$ vs. baseline; ${ }^{+} p \leq 0.05$ vs. injury; ${ }^{*} p \leq 0.05$ vs. G1. 
Analysis of complacency $\left(\mathrm{mL} / \mathrm{cm} \mathrm{H}_{2} \mathrm{O}\right)$

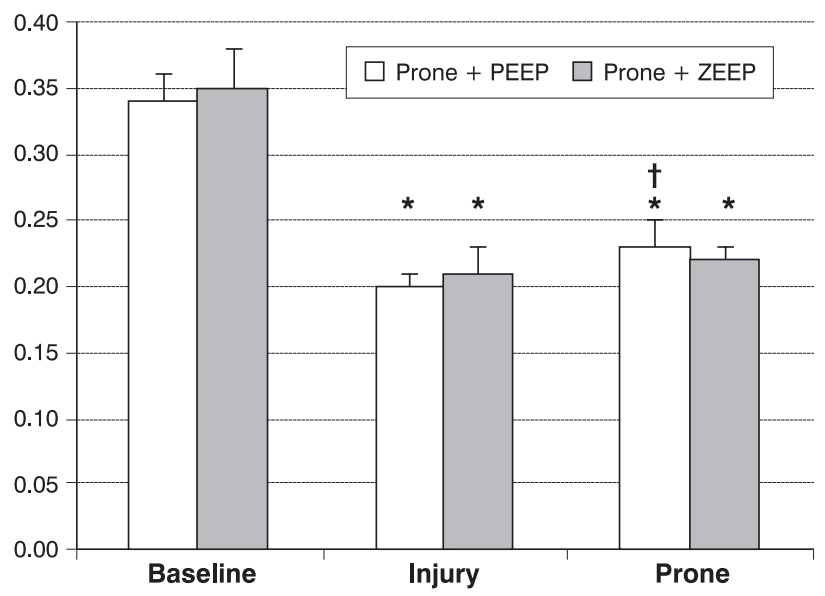

$* p \leq 0.001$ vs. baseline, ${ }^{\dagger} p \leq 0.05$ vs. injury.

Figure 2 - Complacency of the two groups

could change the hemodynamics, particularly in rats, leading to instability which could cause the death of the animals and rule out completion of the experiment. It was also observed that PEEP at higher levels than these reduces cardiac output, making it difficult to interpret gas exchange, since it is known that hemodynamic changes can substantially affect gas exchange. Furthermore, this level of PEEP is often used within the pediatric age range. ${ }^{24}$

Most studies show that the prone position alone does not alter cardiac output. In our experiments, although we did not measure cardiac output, MAP was constant for both groups, suggesting that cardiovascular hemodynamics were unaltered.

Our study of the prone position was for 30 minutes, a period during which, $90 \%$ of patients in clinical trials who responded with improved gas exchange had already done so. ${ }^{13}$ Nevertheless, some patients improve after 120 minutes, so that, if the clinical results were similar to experimental ones, it is possible that after a longer interval we could have observed an improvement in arterial oxygenation.

Despite the use of the prone position to improve arterial oxygenation in patients with ARDS, few studies have investigated the local mechanism behind this improvement. Lamm et al. ${ }^{19}$ demonstrated that the prone position was associated with a stricter distribution of the ventilation /perfusion ratio (more homogeneous) and with a relative increase in the ventilation/perfusion ration in the dorsal region of the lungs.

Computerized tomography of the chest shows that, while ARDS injuries are heterogeneous, they primarily affect the dorsal regions of the lungs. ${ }^{21}$ Therefore, in the supine position, pulmonary ventilation without PEEP is primarily distributed to the ventral region of the lungs. The ratio of ventilation between ventral and dorsal regions is around 2.5:1. With the addition of PEEP, the distribution of ventilation becomes progressively more homogeneous, with the ratio of close to $1: 1$ with PEEP at $20 \mathrm{cmH}_{2} \mathrm{O} .{ }^{25}$ This finding suggests that with PEEP regional complacency is changed, leading to a reduction in the ventral region and an increase in the dorsal region, due to the large quantity of potentially recruitable tissue.

With ARDS and the prone position, the distribution of trans-pulmonary pressure is more homogeneous than with the supine position. Pulmonary density displaces from the dorsal region to the ventral in addition to more homogeneous ventilation distribution. Several mechanisms may be causing this change, including the reversal of the weight gradient across the lungs, transfer of the weight of the heart, transfer of abdominal contents and the shape of the thoracic and pulmonary wall. ${ }^{18}$ Were perfusion to respect only the force of gravity, the majority would go to the dorsal region in the supine position, and to the ventral region in the prone position. However, there is data demonstrating that in the prone position, in contradiction to the gravitational gradient, perfusion continues to be greater in the dorsal part of the lungs, despite the influence of several factors such as hypoxic vasoconstriction, vascular obliteration and external compression of vessels. ${ }^{18,26}$ Since the dorsal region is the most perfused and predominantly most injured in ARDS, in the supine position the result is worsening of the pulmonary shunt.

It is not known if the improved gas exchange in the prone position is the result of the restoration of aeration in the shunted regions or due to redistribution to other areas distant from these regions. Richter et al. ${ }^{27}$ performed a study with seven sheep with ARDS due to pulmonary lavage in an attempt to answer the question above, using positron emission tomography (PET) to investigate the regional distribution of pulmonary shunt, aeration, perfusion and ventilation. The authors concluded that, for the model in question, the improved oxygenation was the result of restoration of aeration and reduction of pulmonary shunt in the dorsal region, although perfusion remained in this region, despite a small redistribution to the ventral region, with no common commitment reduction in aeration or increase in shunt in the ventral region. Nevertheless, the critical factor in improving oxygenation was indeed restoration of aeration in the dorsal regions. This finding is consistent with a lower pleural pressure gradient in the prone position, as described earlier.

This is probably what occurred in our study. Without PEEP, the collapsed alveoli in the dorsal region did not open when the rats were placed in the prone position. Perfusion, as has also already been demonstrated, retained the preference for 
this region, and so pulmonary shunt was also maintained. When PEEP was applied, the preferred alveoli in this region (dorsal) opened, with improved $\mathrm{V} / \mathrm{Q}$ ratio and reduced pulmonary shunt. Even with the use of PEEP, perfusion remained greater in the dorsal region in the prone position. If high levels of PEEP were employed, it is possible that even better oxygenation results could be observed, despite controversies over the effects of PEEP in the prone position. ${ }^{28}$

Therefore, we believe there was probably greater homogenization of pulmonary ventilation when we put our rats in the prone position with PEEP at $5 \mathrm{cmH}_{2} \mathrm{O}$. In addition to the areas recruited by PEEP, which improved the V/Q ratio, it is possible that perfusion also favored the improvement in oxygenation that was observed.

Thus, we postulate that the prone position alone would not be capable of improving oxygenation without PEEP in ARDS, in which we know there is a lower quantity of potentially recruitable pulmonary tissue due to the greater numbers of alveoli filled with liquid, which need greater pressure for alveoli to open. Nevertheless, some authors have demonstrated improved oxygenation when patients are placed in the prone position even on ZEEP, such as Vieillard-Baron et al., ${ }^{29}$ who compared ZEEP and PEEP $=6$ $\mathrm{cmH} 2 \mathrm{O}$ in 11 patients with ARDS of pulmonary origin, with severe hypoxemia. However, the difference from our study is that the whole group was placed in the supine position on ZEEP and then with PEEP $=6 \mathrm{cmH}_{2} \mathrm{O}$, and, then the same group was placed in the prone position on ZEEP and PEEP $=6$ $\mathrm{cmH}_{2} \mathrm{O}$, meaning that when the group were put in the prone position on ZEEP, it had already been given a higher end expiratory pressure $\left(6 \mathrm{cmH}_{2} \mathrm{O}\right)$, possibly already recruiting some previously collapsed areas. Many authors have demonstrated improved oxygenation in the prone position, such as Pelosi et al., ${ }^{30}$ however all of these studies used the same PEEP levels which had already been used in the supine position before being put in the prone position. Therefore, the improvement in oxygenation observed is associated with ventilator parameters which promoted or will promote additional alveolar recruitment, which did not happen in our study, since we only observed the effect of the prone position without PEEP.

In relation to pulmonary compliance, results are controversial. Some studies have shown it to drop, and others to rise, when in prone position. It appears that pulmonary compliance depends on the ARDS etiology. When etiology is pulmonary, complacency is reduced, whereas, when it is extrapulmonary, it may increase. The progress of pulmonary compliance depends on the rigidity of the chest wall and on pulmonary recruitment. This is the reason why complacency tends to improve in extrapulmonary ARDS, since there is more pulmonary parenchyma to be recruited. In our study complacency improved with the use of PEEP at $5 \mathrm{cmH}_{2} \mathrm{O}$, but not with ZEEP. We did not measure static complacency, but dynamic complacency, meaning that we cannot rule out the possibility that using PEEP improved airway resistance, increasing pulmonary volume and therefore improving Cdyn.

In an experimental model of ARDS induced by $\mathrm{HCl}$, which is a model that mirrors bronchoaspiration, primarily common among pre-terms, we observed that the prone position only offered improvements in oxygenation during the first 30 minutes when combined with positive end expiratory pressure $\left(\mathrm{PEEP}=5 \mathrm{cmH}_{2} \mathrm{O}\right)$; the prone position also exhibited improvements, during the period studied, in respiratory mechanics for group 1 , but did not exhibit significant improvements in the group 2. However, since the test power was 0.05 , we cannot rule out a beta type error between the injury and prone phases on ZEEP. The prone position did not cause hemodynamic compromise in either group (with or without PEEP).

The conclusion of our study, therefore, is that in order to improve oxygenation in the prone position, it is of fundamental importance that alveoli be opened using PEEP or perhaps alveolar recruitment maneuvers.

\section{Acknowledgements}

I would like to thank CAPES for the bursary I received throughout the research.

\section{References}

1. Ashbaugh DG, Bigelow DB, Petty TL, Levine BE. Acute respiratory distress in adults. Lancet. 1967;2:319-23.

2. Bernard GR, Artigas A, Brigham KL, Carlet J, Falke K, Hudson L, et al. The American-European Consensus Conference on ARDS. Definitions, mechanisms relevant outcomes, and clinical trial coordination. Am J Respir Crit Care Med. 1994;149(3 Pt 1):818-24.

3. Amato MB, Barbas CS, Medeiros DM, Magaldi RB, Schettino GP, Lorenzi-Filho G, et al. Effect of a protective - ventilation strategy on mortality in the acute respiratory distress syndrome. N Engl J Med. 1998;338:347-54.

4. Ventilation with lower tidal volume as compared with traditional tidal volumes for acute lung injury and the acute respiratory distress syndrome. The Acute Respiratory Distress Syndrome Network. N Engl J Med. 2000;342:1301-18.

5. Rotta AT, Kunrath CL, Wiryawan B. O manejo da síndrome do desconforto respiratório agudo. J Pediatr (Rio J). 2003;79 Supl 2:S149-60.

6. Cheng IW, Matthay MA. Acute lung injury and the acute respiratory distress syndrome. Crit Care Clin. 2003;19:693-712.

7. Krause M, Olsson T, Law AB, Parker RA, Lindstrom DP, Sundell $\mathrm{HW}$, et al. Effect of volume recruitment on response to surfactant treatment in rabbits with lung injury. Am J Respir Crit Care Med. 1997; 156(3 Pt 1):862-6.

8. Huang TK, Uyehara CF, Balaraman V, Miyasato CY, Person D, Egan $E$, et al. Surfactant lavage with lidocaine improves pulmonary function in piglets after $\mathrm{HCL}$-induced acute lung injury. Lung. 2004;182:15-25. 
9. Brower RG, Lanken PN, MacIntyre N, Matthay MA, Morris A, Ancukiewicz $M$, et al. Higher versus lower positive endexpiratory pressures in patients with the acute respiratory distress syndrome. N Engl J Med. 2004;351:327-36.

10. Falke KJ, Pontoppidan H, Kumar A, Leith DE, Geffin B, Laver MB. Ventilation with positive end-expiratory pressure in acute lung disease. J Clin Invest. 1972;51:2315-23.

11. Dall'ava-Santucci J, Armaganidis A, Brunet F, Dhainaut JF, Nouira $S$, Morisseau $D$, et al. Mechanical effects of PEEP in patients with adult respiratory distress syndrome. J Appl Physiol. 1990;68:843-8.

12. Mancebo J, Fernández R, Blanch L, Rialp G, Gordo F, Ferrer M, et al. A multicenter trial of prolonged prone ventilation in severe acute respiratory distress syndrome. Am J Respir Care Med. 2006; 173:1233-9.

13. Guerin C, Gaillard S, Lemasson S, Ayzac L, Girard R, Beuret P, et al. Effects of systematic prone positioning in hypoxemic acute respiratory failure. JAMA. 2004;292:2379-87.

14. Gattinoni L, Tognoni G, Pesenti A, Taccone P, Mascheroni D, Labarta $\mathrm{V}$, et al. Effect of prone positioning on the survival of patients with acute respiratory failure. N Engl J Med. 2001;345:568-73.

15. Bruno F, Piva JP, Garcia PC, Einloft P, Fiori R, MennaBarreto S. Efeito a curto prazo da posição prona na oxigenação de crianças em ventilação mecânica. J Pediatr (Rio J). 2001;77:361-8.

16. PiehI MA, Brown RS. Use of extreme position changes in acute respiratory failure. Crit Care Med. 1976;4:13-4.

17. Douglas WW, Rehder K, Beynen FM, Sessler AD, Marsh HM. Improved oxygenation in patients with acute respiratory failure: the prone position. Am Rev Respir Dis. 1977; 115:559-66.

18. Pelosi P, Brazzi L, Gattinoni L. Prone position in acute respiratory distress syndrome. Eur Respir J. 2002;20:1017-28.

19. Lamm WJ, Graham MM, Albert RK. Mechanism by which the prone position improves oxygenation in acute lung injury. Am J Respir Crit Care Med. 1994;150:184-93.

20. Broccard A. Positive end-expiratory pressure or prone position: is that the question? Crit Care Med. 2003;31:2802-3.

21. Gattinoni L, Pelosi P, Suter PM, Pedoto A, Vercesi P, Lissoni A. Acute respiratory distress syndrome caused by pulmonary and extrapulmonary disease. Different syndromes? Am J Respir Crit Care Med. 1998;158:3-11.
22. Lim MC, Kim EK, Lee JS, Shim TS, Lee SD, Koh Y, et al. Comparison of the response to the prone position between pulmonary and extrapulmonary acute respiratory distress syndrome. Intensive Care Med. 2001;27:477-85.

23. Gainnier M, Michelet P, Thirion X, Arnal JM, Sainty JM, Papazian L. Prone position and positive end-expiratory pressure in acute respiratory distress syndrome. Crit Care Med. $2003 ; 31: 2719-26$

24. Farias JA, Frutos F, Esteban A Casado Flores J, Retta A, Baltodano $A$, et al. What is the daily practice of mechanical ventilation in pediatric intensive care units? A multicenter study. Intensive Care Med. 2004;30:918-25.

25. Johansson MJ, Wiklund A, Flatebo T, Nicolaysen A, Nicolaysen G, Walther SM. Positive end-expiratory pressure affects regional redistribution of ventilation differently in prone and supine sheep. Crit Care Med. 2004;32:2039-44.

26. Richard JC, Decailliot F, Janier M, Annat G, Guérin C. Effects of positive end-expiratory pressure and body position on pulmonary blood flow redistribution in mechanically ventilated normal pigs. Chest. 2002;122:998-1005.

27. Richter T, Bellani G, Scott Harris R, Vidal Melo MF, Winkler T, Venegas JG, et al. Effect of prone position on regional shunt, aeration, and perfusion in experimental acute lung injury. Am J Respir Crit Care Med. 2005;172:480-7.

28. Lim CM, Koh Y, Chin JY, Lee JS, Lee SD, Kim WS, et al. Respiratory and haemodynamic effects of the prone position at two different levels of PEEP in a canine acute lung injury model. Eur Respir J. $1999 ; 13: 163-8$.

29. Vieillard-Baron A, Rabiller A, Chergui K, Peyrouset O, Page B, Beauchet $A$, et al. Prone position improves mechanics and alveolar ventilation in acute respiratory distress syndrome. Intensive Care Med. 2005;31:220-6.

30. Pelosi P, Tubiolo D, Mascheroni D, Vicardi P, Crotti S, Valenza F, et al. Effects of the prone position on respiratory mechanics and gas exchange during acute lung injury. Am J Respir Crit Care Med. 1998; 157:387-93.

Correspondence:

Ana Cristina Zanon Yagui

Rua Sararé, 287/103, Alto de Pinheiros

CEP 05452-010 - São Paulo, SP - Brazil

E-mail: anac.yagui@gmail.com 